\title{
Simultaneous Determination of Two Potential Genotoxic Impurities in Zolmitriptan Using Liquid Chromatography- Tandem Mass Spectrometry
}

\author{
N. VENUGOPAL, A. VIJAYA BHASKAR REDDY and G. MADHAVI* \\ Department of Chemistry, Sri Venkateswara University, Tirupati, A.P.-517502, India \\ gmchem01@gmail.com
}

Received 25 September 2013 / Accepted 8 November 2013

\begin{abstract}
The detection and quantification of potential genotoxic impurities (PGIs) play an important role in the pharmaceutical industry. The industry needs highly selective and sensitive analytical methods for trace level quantification of these PGIs in drug substances. A sensitive and stability indicating LC-MS/MS method was developed for the simultaneous detection and quantification of (S)-4-(4-aminobenzyl)-1,3-oxazolidin-2-one (ABO) and (S)-4-(4-nitrobenzyl)1,3-oxazolidin-2-one (NBO) PGIs in zolmitriptan. Method utilizes, Hypersil BDS C18 column $(50 \mathrm{~mm} \times 4.6 \mathrm{~mm}, 3.0 \mu \mathrm{m})$ with electrospray ionization in selective ion recording (SIR) mode for quantitation of $\mathrm{ABO}$ and NBO PGIs. The method validated as per International Conference on Harmonization (ICH) guidelines and is able to quantitate $\mathrm{ABO}$ at $0.1 \mathrm{ppm}$ and $\mathrm{NBO}$ at $0.2 \mathrm{ppm}$ with respect to $2.0 \mathrm{mg} / \mathrm{mL}$ of zolmitriptan. The method was linear in the range of $0.1-2.0 \mathrm{ppm}$ for $\mathrm{ABO}$ and $0.2-2.0 \mathrm{ppm}$ for NBO which matches the range of LOQ-200\% of specification level $(1.0 \mathrm{ppm})$. The correlation coefficient obtained was $>0.999$ in both the cases. The impurities were not present in the three studied pure and formulation batches of zolmitriptan. The accuracy of the method was ranged between $98.6-102.5 \%$ for both ABO and NBO PGIs. The developed method is a good quality control tool to monitor $\mathrm{ABO}$ and NBO PGIs in zolmitriptan during its manufacture.
\end{abstract}

Keywords: linearity, ICH guidelines, Genotoxicity, Zolmitriptan, LC-MS/MS, Recovery; Stability

\section{Introduction}

The issue of genotoxic impurities has received considerable attention in recent years. Detection and quantitation of potential genotoxic impurities (PGIs) in pharmaceutical formulations are of increasing concern to pharmaceutical industries and regulatory agencies $^{1,2}$. Unfortunately, the nature of the chemical reactivity of PGIs often translates into biological reactivity, and these PGIs can often be mutagens and/or carcinogens ${ }^{3-5}$. As a consequence, presence of even low levels of such impurities may be of significant toxicological relevance for clinical trial subjects and patients ${ }^{6-8}$. Due to this reason, quantification of PGIs in drug substances receiving considerable interest. Although PGIs are carcinogenic, in most of the cases their use cannot be avoided. For this reason EMEA introduced 
the use of a "Threshold of Toxicological Concern" (TTC), which refers to an exposure level that does not pose a significant risk for carcinogenic effects ${ }^{9}$. A TTC of $1.5 \mu \mathrm{g} /$ day for each impurity is considered as an acceptable threshold for supporting a marketing authorization application by EMA or US FDA ${ }^{10,11}$. Due to this defined threshold value, the analytical testing limits required for the detection of selected PGIs are often in the $\mu \mathrm{g} / \mathrm{g}$ depending on the dosage of the active pharmaceutical ingredient (API $)^{12,13}$. One of the biggest scientific challenges facing the pharmaceutical analyst has been the need for rapid development of extremely sensitive and robust analytical methodologies that can adequately monitor potentially genotoxic impurities at these very low levels. The major issues are sensitivity, selectivity and the related problem of overcoming matrix interference in APIs. Therefore gas chromatography (GC) or liquid chromatography (LC) hyphenated with MS has been demonstrated as the most versatile approach in the analysis of PGIs.

Zolmitriptan, 4(S)-4-[3-(2-dimethylaminoethyl)-1H-5-indolylmethyl]-1,3-oxazolan-2one belongs to a group of medicines known as Serotonin 5-HT1D receptor agonist ${ }^{14,15}$. It causes constriction of the blood vessels thereby relieving the pain due to migraine headache. NBO and ABO are commonly used intermediates in the synthesis of zolmitriptan, which are also identified as potential genotoxic impurities (PGIs) ${ }^{16}$. Based on the maximum daily dosage of zolmitriptan, its PGIs are required to be controlled at a limit of $75 \mu \mathrm{g} / \mathrm{g}$. Several analytical HPLC methods were reported in literature for the quantitative determination of zolmitriptan and its metabolites in human plasma and other biological fluids ${ }^{17-21}$. Two stability indicating HPLC methods for related substances in zolmitriptan were also reported ${ }^{22,23}$, but in the reported two HPLC methods the run time is over 60 min and the detection levels are also high. To avoid the long run time and to minimize the quantification levels LCMS/MS have been explored as useful approach.

In the present study we have developed a simple LC-MS/MS method that can quantify at permitted levels of $\mathrm{ABO}$ and NBO PGIs in zolmitriptan. To the best of our knowledge, this is the first analytical approach based on LC-ESI-MS for the detection and quantification of ABO and NBO PGIs simultaneously. The method validated as per ICH guidelines in terms of limit of detection (LOD), limit of quantification (LOQ), linearity, precision, accuracy, specificity and robustness.

\section{Experimental}

All chemicals and solvents were of analytical grade. HPLC grade acetonitrile and ammonium acetate were purchased from Merck (Mumbai, India). Formic acid, trifluoroaceticacid and methanol were obtained in their highest grade from SD fine chemicals limited (Mumbai, India). Reference substances of $\mathrm{ABO}$ and $\mathrm{NBO}$ were obtained from Sigma-Aldrich (St.Louis, MA, USA). High pure Milli-Q water was used with the help of Millipore Milli-Q plus purification system (Bedford, MA, USA).

\section{Preparation of stock and standard solutions}

A stock solution of zolmitriptan $(2.0 \mathrm{mg} / \mathrm{mL})$ was prepared by dissolving appropriate amount in methanol. A stock solution of mixture of PGIs (ABO and NBO) at $0.2 \mathrm{mg} / \mathrm{mL}$ was also prepared in methanol. The diluted stock solution of PGIs (at $0.01 \mathrm{mg} / \mathrm{mL}$ ) was prepared by diluting $2.5 \mathrm{~mL}$ of the $0.2 \mathrm{mg} / \mathrm{mL}$ solution to $50 \mathrm{~mL}$ with methanol. Then $0.2 \mu \mathrm{g} / \mathrm{mL}$ diluted stock solution was prepared by diluting $2.0 \mathrm{~mL}$ of $0.01 \mathrm{mg} / \mathrm{mL}$ diluted stock solution to $100 \mathrm{~mL}$ with methanol. The working standard solution was prepared by accurately weighed $50 \mathrm{mg}$ of zolmitriptan into $10 \mathrm{~mL}$ volumetric flask and made up the solution to the graduation mark after adding $10 \mu \mathrm{L}$ of $0.2 \mu \mathrm{g} / \mathrm{mL}$ diluted stock solution to give 
$2.0 \mathrm{ng} / \mathrm{mL}$ and $2.0 \mathrm{mg} / \mathrm{mL}$ of PGIs with respect to zolmitriptan which correspond to $1.0 \mathrm{ppm}$ of PGIs contamination relative to the drug substance. The PGI samples for validation at $0.10,0.20,0.50,0.75,1.0,1.5$ and $2.0 \mathrm{ppm}$ concentrations relative to the drug substance were prepared in the same manner using $0.2 \mu \mathrm{g} / \mathrm{mL}$ diluted stock solution. The concentration of the standard solutions and samples were optimized to achieve a desired signal-to-noise ratio $(\mathrm{S} / \mathrm{N})$ and good peak shape. All the standards were sonicated well and filtered through $0.22 \mu \mathrm{m}$ membrane filters before the analysis.

\section{LC-MS/MS operating conditions}

The MS/MS system used was an Applied Biosystems Sciex API 4000 model (Switzerland) triple quadruple mass spectrometer with electrospray ionization (ESI) probe coupled with HPLC system consisting of LC-20AD binary gradient pump, a SPD-10AVP UV detector, SIL-10HTC auto sampler and a column oven CTO-10ASVP (Shimadzu Corporation, Kyoto, Japan). The analytical column used was Hypersil BDS C18 (50 mm $\times 4.6 \mathrm{~mm}, 3.0 \mu \mathrm{m})$ in isocratic mode using $5.0 \mathrm{mM}$ ammonium acetate as mobile phase $\mathrm{A}$ and mixture of acetonitrile-methanol $(80: 20, \mathrm{v} / \mathrm{v})$ as mobile phase $\mathrm{B}$ in the ratio of $65: 35(\mathrm{v} / \mathrm{v})$. The flow rate maintained at $0.7 \mathrm{~mL} / \mathrm{min}$ and the column oven temperature was maintained as $35{ }^{\circ} \mathrm{C}$. The sample cooler temperature was set to $10{ }^{\circ} \mathrm{C}$ and the applied injection volume was $10 \mu \mathrm{L}$. Positive ion electro spray ionization probe operated with SIR mode for quantification of both $\mathrm{ABO}$ and NBO PGIs. The two PGIs ABO and NBO were monitored at their molecular ions $[\mathrm{M}+\mathrm{H}]^{+} \mathrm{m} / \mathrm{z}$ 132.1 (protonated) and $[\mathrm{M}+\mathrm{H}]^{+} \mathrm{m} / \mathrm{z} 223.2$ (protanated) respectively, zolmitriptan was monitored with its molecular ion $[\mathrm{M}+\mathrm{H}]^{+} \mathrm{m} / \mathrm{z} 288.2$ (protonated). The ion spray voltage (V), declustering potential (DP) and entrance potential (EP) were kept as $4500 \mathrm{~V}, 52 \mathrm{~V}$ and $52 \mathrm{~V}$ respectively. The curtain gas flow, ion source gas 1 and ion source gas2 nebulisation pressure (psi) were maintained as 22 psi, 25 psi and 14 psi respectively. All the solutions were filtered through $0.22 \mu \mathrm{m}$ membrane filters before the analysis.

\section{Validation study}

The developed method was fully validated in terms of specificity, linearity, limit of quantification (LOQ), limit of detection (LOD), accuracy, precision, robustness and solution stability.

The linearity was evaluated by preparing and analyzing six point calibration curves in the range of 0.1-2.0 ppm for $\mathrm{ABO}$ and 0.2-2.0 ppm for NBO. The slope, intercept and regression coefficient values were determined by the least squares linear regression analysis. The precision was evaluated at two levels viz., repeatability and intermediate precision. Repeatability was checked by calculating the relative standard deviation (RSD) of six replicate determinations by injecting six freshly prepared standard solutions containing both $\mathrm{ABO}$ and NBO PGIs on the same day. The same experiments were done on six different days to evaluate intermediate precision. Limit of detection (LOD) and limit of quantification (LOQ) were evaluated by considering the each PGIs concentration that would give a signalto-noise $(\mathrm{S} / \mathrm{N})$ ratios of $3: 1$ and 10:1, respectively. The LOD and LOQ values were experimentally verified by six injections of standard solutions of the compounds at the predicted concentrations. Recovery of the method was performed by standard addition method to evaluate accuracy and specificity. Accordingly, the accuracy of the method was determined by spiking at LOQ, $0.5 \mathrm{ppm}$ and $1.0 \mathrm{ppm}$ of ABO and NBO separately to three batches of pure and three formulation batches of zolmitriptan. The robustness of the method was studied with slight modifications in flow rate of the mobile phase and column temperature. The flow rate of the mobile phase was $0.7 \mathrm{~mL} / \mathrm{min}$ and the same was altered by 
$10 \%$ of flow i.e. from 0.63 to $0.77 \mathrm{~mL} / \mathrm{min}$. The effect of column temperature on resolution was studied at $33{ }^{\circ} \mathrm{C}$ and $37{ }^{\circ} \mathrm{C}$ (altered by $2{ }^{\circ} \mathrm{C}$ ). Stability of the ABO and NBO PGIs in sample solution was studied by analyzing spiked sample solution at different time intervals at room temperature.

\section{Results and Discussion}

\section{Method development}

The object of the present LC-MS/MS method was to separate and quantify ABO and NBO PGIs simultaneously in zolmitriptan. The signal intensity observed for $\mathrm{ABO}$ and NBO in positive mode was much higher than that in negative mode. Then, the possibility of using electrospray ionization (ESI) or atmospheric pressure chemical ionization (APCI) sources under positive ion detection mode was evaluated during the early stages of method development. ESI spectra revealed higher signals for the impurities compared to APCI source. Therefore, further method development was limited to ESI source in positive mode. Then, the chromatographic parameters were optimized by altering stationary and mobile phases sequentially and observed their efficiency. As a preliminary investigation, different columns with various dimensions were tested viz., Symmetry C18, Atlantis C8 and Hypersil BDS C18, but the response and peak shape were very poor with all columns except Hypersil BDS C18 $(50 \mathrm{~mm} \times 4.6 \mathrm{~mm}, 3.0 \mu \mathrm{m})$. During the mobile phase optimization a mixture of $0.1 \%$ formic acid-acetonitrile and $0.1 \%$ formic acid-methanol with different compositions were investigated, with $0.1 \%$ formic acid-methanol $(60: 40, \mathrm{v} / \mathrm{v})$ all the compounds were eluted but the peak shape and response were very poor, then it was planned to change the mobile phase and finally proper peak shape and good separation was obtained with a mixture of $5.0 \mathrm{mM}$ ammonium acetate-(acetonitrile-methanol, 80:20, v/v) with a ration of 65:35, v/v. Hence using Hypersil BDS C18 column and a mixture of ammonium acetate-(acetonitrile-methanol, 80:20 v/v) in $65: 35,(\mathrm{v} / \mathrm{v})$ ratio was found to be suitable for quantification of ABO and NBO PGIs.

\section{Method validation}

The developed method for simultaneous quantification of $\mathrm{ABO}$ and NBO PGIs in zolmitriptan was validated as per ICH guidelines.

\section{System suitability}

The system suitability test was performed before each run to assure that the developed analytical method exhibits satisfactory performance. Repeatability in system performance was measured as relative standard deviation (RSD) of six injections of standard solution. The resulted RSD value was found to be $<1.0 \%$.

\section{Selectivity and Specificity}

The method selectivity was established using LC-MS/MS analysis of blank (sample solvent) and samples spiked with impurities. Both PGIs and zolmitriptan solutions prepared individually in the diluent and a solution of zolmitriptan spiked with ABO and NBO PGIs were also prepared and injected for evaluation of specificity. No interfering co-eluting peaks in sample solvent were observed, which demonstrated the selectivity and specificity of the developed LC-MS/MS method (Figure 1).

\section{Limit of Detection (LOD) and Limit of Quantification (LOQ)}

LOD and LOQ were calculated for $\mathrm{ABO}$ and NBO PGIs based on signal-to-noise ratio $(\mathrm{S} / \mathrm{N})$. To determine LOD and LOQ values $\mathrm{ABO}$ and $\mathrm{NBO}$ concentrations were reduced 
sequentially such that they yield $\mathrm{S} / \mathrm{N}$ ratio as $3: 1$ and 10:1 respectively. The LOD and LOQ of $\mathrm{ABO}$ were found to be $0.03 \mathrm{ppm}$ and $0.1 \mathrm{ppm}$, respectively, whereas for NBO the LOD and LOQ values were $0.06 \mathrm{ppm}$ and $0.2 \mathrm{ppm}$, respectively. The determined LOD and LOQ chromatograms were shown in Figure 2 and Figure 3, respectively. Repeatability was checked from RSD value of six injections at predicted LOD and LOQ concentrations (Table 1). The observed RSD value in each case was $<3.0 \%$.
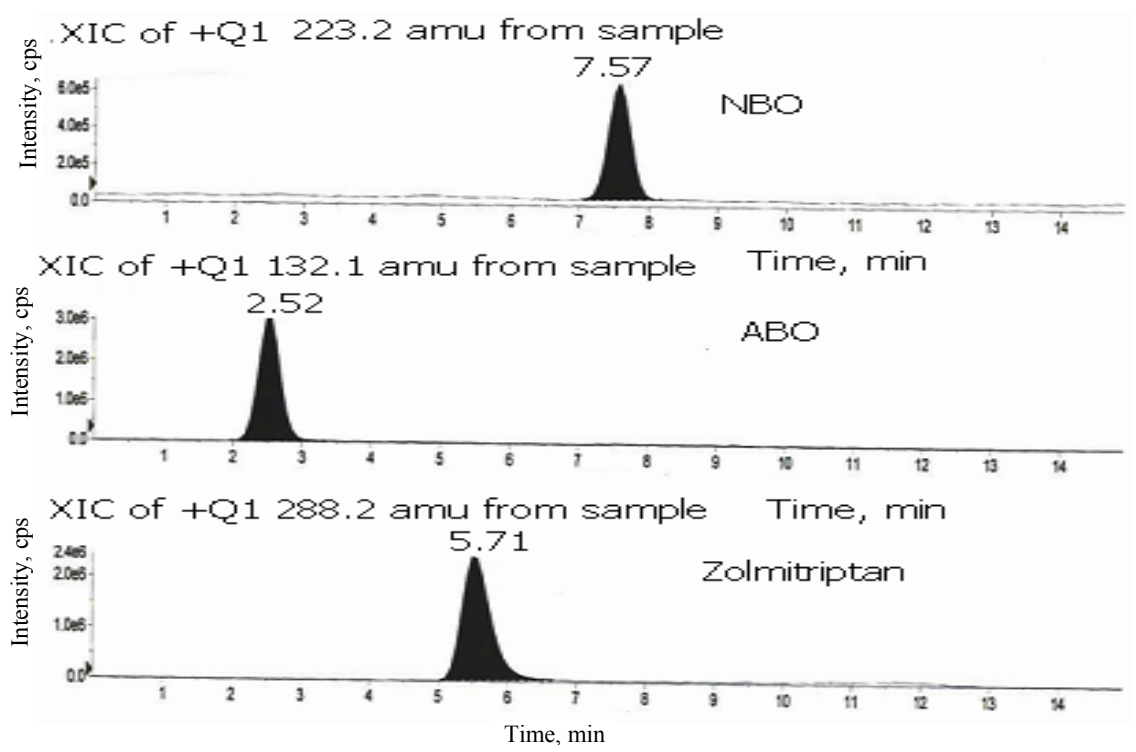

Figure 1. Specificity chromatogram of ABO and NBO PGIs in presence of zolmitriptan

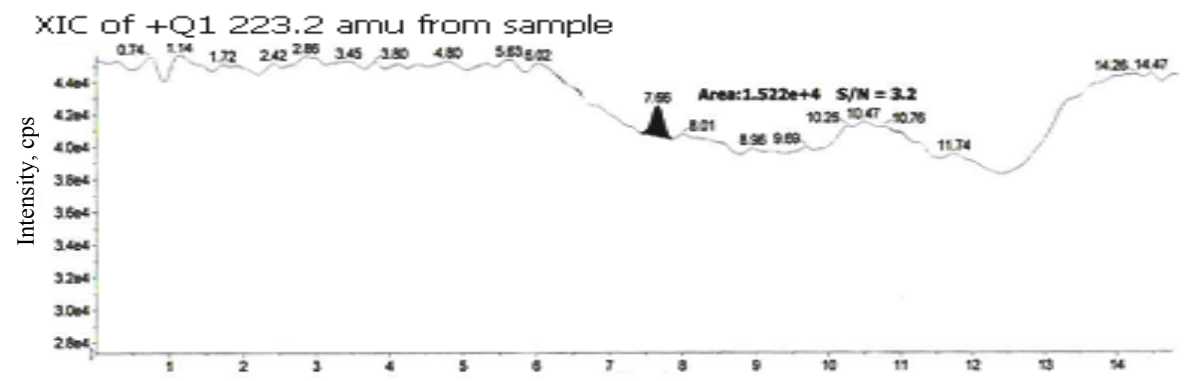

$\mathrm{XIC}$ of $+Q 1132.1$ amu from sample

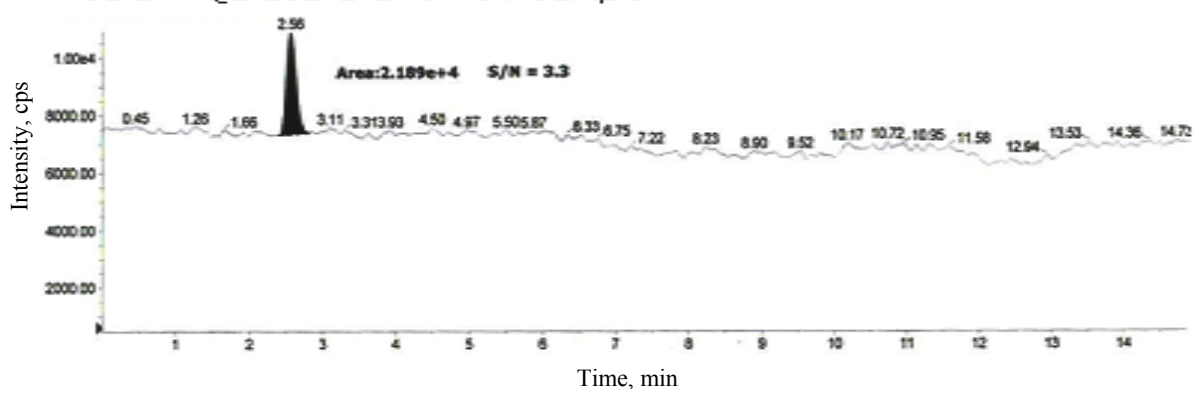

Figure 2. LOD chromatogram of $\mathrm{ABO}$ and NBO PGIs 


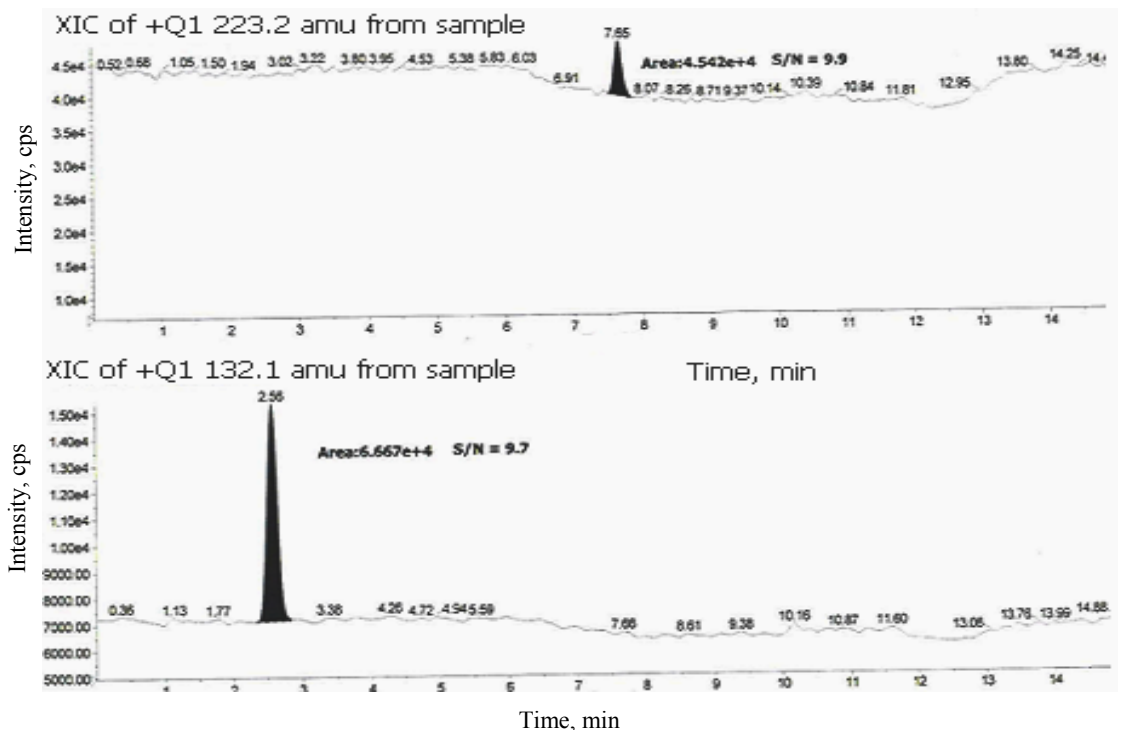

Figure 3. LOQ chromatogram of ABO and NBO PGIs

\section{Linearity}

The linearity experiment was conducted for both the PGIs at the concentration range from LOQ to $200 \%$ of the specification limit, which showed that mass spectrometric responses were proportional to their concentration within the range of $0.1-2.0 \mathrm{ppm}$ for $\mathrm{ABO}$ and $0.2-$ $2.0 \mathrm{ppm}$ for NBO. A linear calibration graph was obtained over the concentration range of 0.1-2.0 ppm for ABO and 0.2-2.0 ppm for NBO PGIs. The correlation coefficient obtained was more than 0.9998 in both the cases (Table 1). The results revealed that an excellent correlation existed between the peak areas and concentrations of both ABO and NBO PGIs.

\section{Precision, Accuracy and determination in bulk samples}

The precision of the method was verified at two levels viz., repeatability and intermediate precision. Repeatability was checked by calculating the relative standard deviation (RSD) of six replicate determinations by injecting six freshly prepared solutions containing both impurities on the same day. The same experiments were done on six different days for evaluating intermediate precision. The RSD value for repeatability studies was $<1.0 \%$, whereas the RSD for inter day precision was higher than that of repeatability study, which was around $3.0 \%$. The recovery studies by the standard addition method were performed to evaluate accuracy and specificity, accordingly the accuracy of the method was determined in triplicate at LOQ level in three batches of pure and formulation samples individually. Then the percentage recoveries were calculated. Excellent recovery values for both PGIs were obtained. At such a low levels these recoveries were satisfactory and RSD was calculated from the average of triplicate analysis and the resulted RSD value is $<2.0 \%$. The corresponding data was shown in Table 1.

\section{Robustness}

The robustness of the method was studied with deliberate modifications in flow rate of mobile phase and column temperature. The flow rate of mobile phase was altered by $10 \%$ of its flow i.e $0.63 \mathrm{~mL} / \mathrm{min}$ to $0.77 \mathrm{~mL} / \mathrm{min}$. The effect of column temperature on resolution was studied at $33{ }^{\circ} \mathrm{C}$ and $37{ }^{\circ} \mathrm{C}$ (temperature altered by $2{ }^{\circ} \mathrm{C}$ ), the results obtained was shown in Table 2 , which reveals that chromatographic performance do not affected by these changes. 
Table 1. Method validation summary report

\begin{tabular}{|c|c|c|}
\hline Parameter & $\mathrm{ABO}$ & NBO \\
\hline Linearity ppm & $0.1-2.0$ & $0.2-2.0$ \\
\hline $\mathrm{r}$ & 0.9999 & 0.9997 \\
\hline Slope & 255,720 & 316,520 \\
\hline Intercept & 530.75 & 439.50 \\
\hline LOD ppm & 0.03 & 0.06 \\
\hline LOQ ppm & 0.1 & 0.2 \\
\hline \multicolumn{3}{|l|}{ Precision (\%R.S.D) } \\
\hline $\operatorname{LOD}(n=6)$ & 1.22 & 0.78 \\
\hline $\operatorname{LOQ}(n=6)$ & 2.47 & 0.53 \\
\hline \multicolumn{3}{|l|}{ Precision (intraday) } \\
\hline \% R.S.D $(n=6)$ & 1.25 & 0.76 \\
\hline \multicolumn{3}{|l|}{ Precision (interday) } \\
\hline \% R.S.D $(n=6)$ & 2.74 & 2.16 \\
\hline \multicolumn{3}{|l|}{ Accuracy at LOQ level $(n=3)$} \\
\hline Amount added ppm & 0.1 & 0.2 \\
\hline Amount recovered ppm & 0.0993 & 0.0197 \\
\hline$\%$ recovery & 99.3 & 98.6 \\
\hline$\%$ R.S.D & 0.92 & 0.84 \\
\hline \multicolumn{3}{|l|}{ Accuracy at $100 \%$ level $(n=3)$} \\
\hline Amount added ppm & 1.0 & 1.0 \\
\hline Amount recovered ppm & 0.989 & 1.014 \\
\hline$\%$ recovery & 98.9 & 101.4 \\
\hline$\%$ R.S.D & 1.65 & 1.74 \\
\hline \multicolumn{3}{|l|}{ Accuracy at $150 \%$ level $(n=3)$} \\
\hline Amount added ppm & 1.5 & 1.5 \\
\hline Amount recovered ppm & 1.537 & 1.518 \\
\hline$\%$ recovery & 102.5 & 101.2 \\
\hline$\%$ R.S.D & 1.21 & 1.94 \\
\hline \multicolumn{3}{|l|}{ Solution stability } \\
\hline $\begin{array}{l}\text { Theoretical conc ppm } \\
\% \text { recovery }(n=3)\end{array}$ & 0.1 & 0.2 \\
\hline at $0 \mathrm{~h}$ & $98.2 \pm 0.81$ & $96.2 \pm 0.68$ \\
\hline $12 \mathrm{~h}$ & $101.4 \pm 1.02$ & $103.8 \pm 0.77$ \\
\hline $24 \mathrm{~h}$ & $97.6 \pm 0.49$ & $96.4 \pm 0.28$ \\
\hline $36 \mathrm{~h}$ & $99.8 \pm 0.91$ & $100.4 \pm 1.21$ \\
\hline
\end{tabular}

$n$ : number of determinations; $r$ : correlation co-efficient; LOD: limit of detection; LOQ: limit of quantification

Table 2. Robustness data for NBO and ABO PGIs at LOD and LOQ concentrations

\begin{tabular}{lccc}
\hline \multicolumn{1}{c}{ Parameter } & Actual & Low & High \\
\hline Flow variation & 0.7 & 0.63 & 0.77 \\
Column oven temperature, ${ }^{\circ} \mathrm{C}$ & 35 & 33 & 37 \\
NBO & & & \\
\%R.S.D at LOD & 1.22 & 1.38 & 1.46 \\
\%R.S.D at LOQ & 2.48 & 1.88 & 2.74 \\
ABO & & & \\
\%R.S.D at LOD & 0.78 & 1.21 & 0.94 \\
\%R.S.D at LOQ & 2.43 & 2.13 & 1.66 \\
\hline
\end{tabular}




\section{Solution stability}

Both ABO and NBO PGIs were found stable in diluent at room temperature for $36 \mathrm{~h}$ in presence of zolmitriptan, which indicates the suitability of diluent, making the analysis more practicable. The values for the percent change for the above stability experiment were compiled in Table 1. The recoveries of stock solution at different time intervals are within 97.6-103.8\% of their nominal values. The results obtained are then compared with the method precision results. The difference between recoveries at $0^{\text {th }} \mathrm{h}$ and $36^{\text {th }} \mathrm{h}$ are not more than $10 \%$.

\section{Conclusion}

The proposed method is a direct tandem mass spectrometric method for detection and quantification of ABO and NBO PGIs in zolmitriptan. The described analytical method is cost-effective, direct, accurate and convenient quality control tool for determination of both ABO and NBO PGIs. The method was completely validated, and showing satisfactory data for all the method validation parameters tested. The method is linear over a wide concentration range i.e. LOQ- $200 \%$ of specification level. The developed method is stability indicating and can be used for the routine analysis of production samples and also to check the stability of bulk samples of zolmitriptan.

\section{Acknowledgement}

One of the authors Mr. A. Vijaya Bhaskar Reddy is highly grateful to the UGC (BSR), Government of India, New Delhi for financial assistance in the form of an award of Meritorious Research Fellowship (RFSMS).

\section{References}

1. ICH Q9, Quality Risk Management, June, 2006.

2. ICH Q8, Pharmaceutical Development: May, 2006.

3. European Medicines Agency, Guideline on the Limits of Genotoxic Impurities: 28 June, 2006.

4. Bouder F, Expert Rev Clin Pharmacol., 2008, 1(2), 241-250; DOI:10.1586/17512433.1.2.241

5. IARC Monographs Program on the Evaluation of Carcinogenic Risks to Humans for Methyl Methanesulfonate., 1999, 71, 1059.

6. Kondo K, Watanabe A, Iwanaga Y, Abe I, Tanaka H, Nagaoka M H, Akiyama H and Maitani T, Food Addit Contam., 2006, 23(11), 1179-1186.

7. Jacobson Kram D, McGovern T, Adv Drug Deliv Rev., 2007, 59(1), 38-42; DOI:10.1016/j.addr.2006.10.007

8. Kroes R, Renwick A G, Cheeseman M, Kleiner J, Mangelsdorf I, Piersma A, Schilter B, Sclatter J, Van Schothorst F, Vos J G and Wurtzen G, Food Chem Toxicol., 2004, 42(1), 65-83; DOI:10.1016/j.fct.2003.08.006

9. The European Medicines Agency [EMA], Guidelines on the Limits of Genotoxic Impurities, CPMP/SWP/5199/02, June 2006.

10. Dobo K L, Greene N, Cyr M O, Caron S and Ku W W, Regul Toxicol Pharmcol., 2006, 44(3), 282-293; DOI:10.1016/j.yrtph.2006.01.004

11. US FDA, Guidance for Industry: Genotoxic and Carcinogenic Impurities in Drug Substances and Products: Recommended Approaches (Draft), June 2008.

12. Jacobson Kram D and Jacobs A, Int J Toxicol., 2005, 24(3), 129-134; DOI:10.1080/10915810590952933 
13. Venugopal N, Vijaya Bhaskar Reddy A, Gangadhara Reddy K, Madhavi V and Madhavi G, J Pharm Biomed Anal., 2012, 70, 592-597; DOI:10.1016/j.jpba.2012.05.031

14. Johnson K W, Schaus J M, Durkin M M, Audia J E, Kaldor S W, Flaugh M E, Adham N, Zgombick J M, Cohen M L, Branchek T A and Phebus L A, Neuroreport, 1997, 8(9-10), 2237-2240.

15. Whale R, Bhagwagar Z and Cowen P J, Psychopharmacology. 1999, 145(2), 223226; DOI:10.1007/s002130051052

16. Ashby J and Tennant R W, Mutat. Res., 1988, 204, 17-115.

17. He H, Meng H, Zhou Y, Li B and Li X, Yaowu Fenxi Zazhi., 2005, 25(5), 323-325.

18. Yu L, Wen Y, Song Z, Mu D, Su L and Yang Y, Fenxi Ceshi Xuebao., 2006, 25, 67-70.

19. Chen J, Jiang X G, Jiang W M, Mei N, Gao X L and Zhang Q Z, J Pharm Biomed Anal., 2004, 35(3), 639-645; DOI:10.1016/j.jpba.2004.01.019

20. Yao J, Qu Y, Zhao X, Hu L, Zhu R, Li H and Ding J, J Chinese Pharm Sci., 2005, 14, 25-28.

21. Clement E M and Franklin M, J Chromatogr B, 2002, 766(2), 339-343;

DOI:10.1016/S0378-4347(01)00470-4

22. Vijaya kumar E K S, Samel M A, Bhalekar S B and Pakhale S M, Indian J Pharm Sci., 2010, 72(1), 119-122.

23. Navaneeswari R and Raveendra Reddy P, African J Sci Res., 2011, 4(1), 229-243. 